\title{
Ethical Considerations in Primate Conservation
}

\author{
Emma Cancelliere* \\ University of Toronto, Canada
}

\begin{abstract}
Primate conservation is often complicated by the presence of human communities competing for shared resources. Considering the finite nature of these resources, this cohabitation can lead to a dilemma wherein a particular community (either non-human primate or human) grows to the detriment of the other. Immediately, this dilemma may be addressed from either an anthropocentric or a non-anthropocentric perspective. The former demands we prioritize our own kind, forgoing non-human primate conservation unless it is also able to benefit human communities. Alternatively, primate conservation can be approached non-anthropocentrically through initiatives that seek to extend basic human rights to the great ape family. Such "live-and-let-live" programs are difficult to enforce and often face scrutiny and scepticism by nearby human communities. While including local communities as agents of conservation may appear to solve the dilemma, such approaches are derived from a cost-benefit system where conservation agendas are upheld only as long as they benefit the local people executing them. This prioritization is potentially solvable by a deeper ecological understanding of both human and non-human primates and their reciprocal relationship. Such a profound change, however, will require long-term, sustained effort and fails to improve primate conservation adequately in the short term. Thus, primate conservation will continue to balance and reconcile the needs of both human and primate communities as our understanding of this delicate relationship continues to build.
\end{abstract}


Approximately half of the world's primates are endangered (Riley, 2010, p. 235), a statistic we have become accustomed to hearing on sensationalized television specials. The irony of the primates' situation is in the advertisements interrupting these documentaries that showcase starving orphans and impoverished villages. The nonhuman primate also struggles: lacking water, arable land, and the economic means to survive, nearby human populations are also at risk. Both populations make their homes on the same land and require many of the same resources. Additionally, each of the cohabiting populations often develops to the detriment of the other (Treves et al, 2006, p. 383). Given the finite ecological space and resources, there is competition between the two for domination of an area, and our resources to aid either population are inherently limited. Thus, a decision to help one population is often a decision to indirectly harm the other. The limits in our, and the environment's, resources create a moral dilemma when it comes to the conservation of primates and nearby humans: which group is to receive priority?

There are two opposing camps in primate conservation. The first implores that we prioritize our own kind; this anthropocentric view dictates that until humans can successfully manage their own communities, resources should focus fully on that cause (Hill, 2002, p.1148; Lovett \& Marshall, 2006, p. 114). Such a human-centric perspective can be justified through an evolutionary framework.

The Darwinian understanding of ecology dictates that an action is best if it increases the reproductive potential of an individual. Failing this, the next best strategy is one that benefits that individual's group, population, or species (Strier, 2011, pp. 96-97). Nowhere in the ecological struggle for survival is there a rule about defending a foreign species unless such an action would directly benefit the decision-making individual. Given that primate conservation often compromises surrounding human communities by limiting their resources (Treves et al, 2006, p. 383), it is unrealistic to expect nearby human populations to defend primates. Likewise, it is ecologically unsound to focus our aid on protecting primate livelihoods when members of our own species struggle.

By focusing aid efforts on humans and prioritizing human livelihoods over conservation goals, anthropocentric ethics on primate conservation indirectly advocate that primate livelihoods are less important than our own. This perspective holds that until we are able to manage our own communities, available resources should be allocated to this cause. Efforts to conserve primates would only be made under this framework if preserving the primates could benefit humans, either directly or indirectly (Rose, 2011, p. 246). Conservation efforts are thus framed through the human perspective. 
One anthropocentric justification for the conservation of primates is biophilia, the human love for and fascination with living beings. Human biophilia is an innate quality that is stronger for creatures that bear a resemblance to us. Being humanoid in appearance and our closest living relatives genetically, primates become instant "bestsellers" in this regard, (Rose, 2011, pp. 247-248). Anthropocentric discourse on conservation focuses on biophilia and the similarities between humans and primates. For example, parallels can be drawn between human and primate hands, concluding that primates are as we are and thus deserve our protection.

In contrast, the issue of primate conservation can be approached from a nonanthropocentric, ecological point of view. This view does not prioritize humans, but neither does it prioritize primates. In essence, these ethics assign equal rights to both populations as individuals; attempting to draw attention to the status of primates as beings with equal moral rights stands as a goal in and of itself (Lovett \& Marshall, 2006, p. 114). Several associations (the Great Ape Project being perhaps the most notable) focus their conservation efforts in assigning human rights_-and not just animal rightsto nonhuman primates and, more specifically, great apes (greatapeproject.org, 2012, paras. 1-2). While the extent of rights assigned to animal rights are contested, basic human rights are firmly established and acknowledged by governments and other institutions. Further, assigning them animal rights reinforces the divide between humans and great apes, necessitating the very ranking systems and need for priorities that grouping them together would avoid. If instead we deem humans and great apes as fitting under the same category of rights, we are levelling the amount each is weighed when discussing conservation or other forms of assistance. Lastly, these legal rights would protect great apes from human exploitation and make human encroachment and habitat destruction prosecutable (greatapeproject.org, N.D. q3). Indirectly, assigning nonhuman primates equal moral rights defends their ability to live in their natural habitats, undisturbed by humans.

The Great Ape Project and other non-anthropocentric initiatives advocate a "liveand-let-live" principle. Non-interference philosophies can be upheld by conservation initiatives that protect specific areas of land from human influence. Unfortunately, these initiatives are wholly dependent on compliance with park boundaries and regulations. While they create laws and legislation that give nonhuman primates rights to exist and flourish safely, these initiatives are only as strong as the legal system in the area. Especially in critical areas where human livelihood suffers and locals may not understand conservationist agendas, patrolling parks and enforcing bans on destructive behaviours can be nearly impossible to implement effectively (Hill, 2002, p.1188; Treves et al, 2006, p. 384). 
Because of these difficulties in maintaining non-anthropocentric initiatives, the trend in conservation is shifting towards initiatives that include local communities as agents. These initiatives are reminiscent of anthropocentric ones in that they focus on local communities. However, unlike anthropocentric agendas (for which the result is a healthy human community to the detriment of primate populations), these efforts use the well-being of primate populations to create healthy human communities. The most obvious method of doing this is by offering local communities livelihood incentives for conserving local primates and protecting their habitats (Hill, 2002 p. 1188; Lovett \& Marshall, 2006, p. 114). By offering incentives to local communities, conservation efforts stand to benefit both populations and seemingly solve the ethical dilemma of prioritizing one over the other.

Nonetheless, these approaches utilize an economic framework to justify primate conservation. The economic approach, similar to the anthropogenic agenda, weighs the costs and benefits of assisting each population. The currency in this framework, however, is not species reproductive potential, but rather livelihood and literal currency. To motivate local communities, external agencies often speak of the benefits outweighing the costs to maintain conservation initiatives. For example, an agency may provide the community with new tree nurseries and educational facilities in exchange for the protection of local forests. In theory, the livelihood generated through these new institutions should be greater than that generated by traditional practises, which are detrimental to primate communities (practices such as hunting and trapping) (Hill, 2002, p. 1189). In these approaches, economic incentives are often negotiated, and communities are compliant as long as their gain is measurable and evident. This can become problematic, as it risks embedding the value of measurable gains and losses in these communities, which may lead to opportunistic conservation.

In his essay "Bonding, biophilia, biosynergy and the future of primates in the wild," Rose (2011) offers two worldviews through which primate conservation can be approached. The first, a synergistic communal worldview, sees the environment in which we live as an integrated holistic system. The second perspective, termed competitive hierarchical, is a more Western worldview. Competitive hierarchical worldviews see the world as a competition that must be won by individuals at any cost to the environment they inhabit. Even in domains like conservation, which seem to be selfless and offer little gain to individuals, the competitive hierarchical worldview drives actions. Therefore, while a conservationist ethic can be reconciled with competitive hierarchical worldviews, such efforts are inherently selfish. For example, a competitive hierarchist who superficially aims to conserve a population is motivated by personal gain (acclaim; 
personal interest in that taxa, etc.) (p. 246). What at first seems selfless is actually yet another match in the game that competitive hierarchists are trying to win.

This competitive rationale explains why corporations or individuals will "embellish their image as wildlife protectors to gain advantage over their corporate competitors for donor funding" (Rose, 2011 p. 246). Competition, even if it is over conservation, is driven by incentive, as with the incentive of grant funding in the above example. Essentially, the framework in which competitive hierarchists operate is capitalistic, anthropocentric, and individualistic, and the methods employed to achieve a goal will reflect these features. Imposing an incentive-centric system on a synergistic communal cultural can trigger a worldview shift into a competitive one. Understanding conservation efforts and the benefits generated from incentive programs may motivate local peoples to comply, but action is ultimately driven by self-interest and not by a desire to see the primates protected.

Theoretically, incentive-based, community-centred programmes should result in higher levels of protection to primates. Successful programs focus on alternative livelihood strategies, giving locals the tools to subsist without encroaching on primate habitats or interfering with primate populations. However, these benefits are dangerous, as they are entirely dependent on the favourableness of primate protection in a cost/benefit analysis. By adopting a competitive, incentive-based perspective on primate conservation, we are inviting the potential consequences of understanding primates as economic units.

For this purpose, economic units can be thought of as any item or substance that can be quantified in terms of gains or losses and considered in terms of trading potential. In this sense, complying with a primate conservation initiative leads a community to gain $\mathrm{X}$ advantage (quantifiable benefits). The presence of primates becomes equivalent to benefit $\mathrm{X}$ and are now measurable units of economic value. The primates have become valuable economically and take on the role of an exploitable resource. From this, it is easy to conjecture a situation in which any behavioural change on the locals' behalf is driven by economic incentive. The primates, as a proxy for economic development, become worth the benefit they bring.

In such a situation, what would occur if a corporation offered the locals a higher price for increased crop yields than the ecotourism industry could offer for continued tourism? Primates, as crop raiders, often interfere with optimizing crop yields (Hill, 2002 p. 1186). The primates now have a fixed value assigned to them by the cashflow generated via touristic activities and other reward-based conservation initiatives. If the 
value of the crops is greater than this value, the locals will have no motivation to comply with conservation programmes. Simply put, since the perspectives on primates have not changed, the farmers have no ethical or moral obligations towards primates. Their moral obligation was to themselves and their economic state, using the primates as tools to succeed in these arenas. It follows that farmers will resume hunting and trapping of primates, seeking still to "win" economically within their anthropocentric, individualistic ethic. Their ethical duty, in this case, is to themselves and not the primates; any perceived benefit to the primate populations is coincidental.

The danger of commodifying primates in this manner does not end at primate communities; given that the incentives to locals are imposed by external agencies, human populations are under similar risk as primates but on a different scale. Similar to how human communities use primates to succeed economically, external agencies often use communities the same way to increase funding, satisfy shareholders, and create "waves" of change. The external agencies, whether NGOs or travel companies, are governed by similar economic ethics that attempt to maximize profits in a justifiable way (Rose, 2011, p. 246). Their moral duty may be not to the communities but to their funders and shareholders. Thus, if it becomes more economically profitable to pull support, or if the desired conservation goals are not being met sufficiently, a community can be abandoned to disastrous outcomes. Problems resulting from withdrawn support have been documented in many cases, such as in Sri Lanka, where the cessation of subsidized pesticide programs (caused by a shift in the economic motivations of an external corporation) led to an inability for farmers to maintain yields at a market level (Fennel, 2010 p. 143). The dramatic financial and livelihood impact this had on these farmers was a consequence of the farmers no longer fitting into the prioritized economic model upheld by the external agencies that had previously funded them.

Approaching conservation with such competitive hierarchal worldviews (anthropocentric, economic ethic) clearly creates ethical and logistical dilemmas. These problems originate from the fact that such ethics take a single unit's perspective and rank other units accordingly; they are ranked systems of priority determined by cost/benefit analyses. Such a ranking system justifies the community abandoning primates at times, just as it justifies corporations abandoning communities. Thus, while approaching conservation at a community level does connect the two groups, it does so through the perspective of only one. Take, for example, the case of orangutans and nearby farmers. To survive, an orangutan needs sufficient food resources. Faced with increasingly fragmented habitats, orangutans try to meet their nutritional requirements by raiding palm fields. Farmers, at the same time, need to protect their crops from orangutans to maximize their economic gain. Individualistic approaches try to balance these two sets of 
needs, but because the ethic acknowledges the contrasting goals, this ethic still calls for prioritization and ranking.

One solution to prioritization is developing a more profound ecological understanding of both groups, as represented in eco-centric or reciprocal relationships between all beings (Baird-Callicot, 2001 p. 79). To refer again to Rose's (2011) definition of a synergistic communal worldview, such an ethic holds that each being has a specific place in an ecological landscape. Removing any being from its place creates the risk of the entire structure collapsing (2011, p. 246). Thus, value and importance are acephalous and cannot be ranked. Neither primates and humans exist to serve the other. Both exist in a continuous state of interaction with other ecological forces in which the only unit of consideration is integrity of the entire system (Baird-Callicot, 2001, p. 79). All beings comprise an integrated whole, and there are no priorities to consider. By this ecological ethic, both the farmer and orangutan still have needs, but there is an understanding that the two are dependent on each other for some needs and tied up in a complex series of ecological relationships for others. Removing or lessening the impact of either will not solve a problem, as it disturbs the integrity of the entire system. This can be seen with great clarity in the role primates play as important seed dispersers in many ecosystems. Likewise, humans thinning forests and hunting primates can sometimes (when done sustainably) benefit primate populations by opening resources and lessening competition (Hill, 2002, pp. 1185-1190). One population's priorities cannot be extracted from this equation, as both populations are intrinsically connected and integrated.

Calling for fundamental change in the way that we conceptualize conservation is not something that is feasible over a short timescale. As of now, research is being conducted to better understand the ethics that communities already hold towards neighbouring primates (Treves et al, 2006, p. 386). While a body of literature builds, current ethics can continue to proceed in the short term. The same goals are attained when hunting and trapping activities are controlled and forest habitats conserved. The change that needs to be made, however, is rather a theoretical one that will strengthen the practical solutions being employed. The understanding of both humans and primates as integral parts of a whole will solidify existing practical solutions and strengthen both the community's motivations to maintain programmes and corporations' motivations to fund them.

Calling for an enduring change in the understanding of primate conservation will lead to more sustainable efforts that are less vulnerable to being abandoned by external agencies and conditions. This will foster a more positive interconnected relationship between primates and humans and thereby ensure the health of both populations in the future. 
*Writer: Emma Cancelliere is an undergraduate student in her third year at the University of Toronto, Canada. She is a biological anthropology specialist with a minor in environmental studies. Her research interests focus on primate behavioural ecology and conservation.

\section{References}

Baird-Callicot, J. (2001). Multicultural environmental ethics. Daedalus, 130(4), 77-97.

Fennel, D. (2010). Ecotourism and the myth of indigenous stewardship. Journal of Sustainable Tourism, 16, 129-149.

Great Ape Project. (2012). GAP project. The Great Ape Project. Retrieved from http://greatapeproject.org

Hill, C. (2002). Primate conservation and local communities - Ethical issues and debates. American Anthropologist 104, 1184-1194.

Lovett, J., \& Marshall, A. (2006). Why should we conserve primates? African Journal of Ecology 44, 113-116.

Riley, E. (2010). The importance of human-macaque folklore for conservation in Lore Lindu National Park, Sulawesi, Indonesia. Oryx, 44(2), 235-240.

Rose, A. (2011). Biophilia, biosynergy, and the future of primates in the wild. American Journal of Primatology 73, 245-252.

Siex, K. \& Struhsaker, T. (1999). Colobus monkeys and coconuts: a study of humanwildlife conflicts. Journal of Applied Ecology, 36, 1009-1020.

Strier, K. (2011). Primate Behavioral Ecology. New Jersey: Prentice Hall

Treves, A., Wallace, R., Naughton-Treves, L., Morales, A. (2006). Co-Managing humanwildlife conflicts: A review. Human Dimensions of Wildlife, 11, 383-396. 